\title{
Putting excellence at the heart of European research
}

Europe's new funding agency, the European Research Council, will award prestigious grants for basic research. This can make Europe a better place to do research, if the Research Council can maintain its independence and momentum.

In Europe, scientists engaged in basic research obtain funding mainly from national sources. Each country makes its own rules for evaluating criteria and level of funding. As a result, the basic research landscape across the continent is a mosaic of quality and financial support. Therefore, the creation of the European Research Council (ERC), formally launched on February 27, 2007, with its mission to support top-level basic science across Europe is a historic opportunity.

For a European funding agency, the ERC concept is revolutionary in several ways. First, its mandate is to sponsor basic research and to award grants to individual investigators. This contrasts with the European Framework Programs, which target large collaborative projects and tend to favor applied research. Second, the applications will be investigator-driven rather than fitting into preimposed research themes. This, it is hoped, will create a flexible structure capable of responding quickly to needs in emerging areas of research.

Most importantly, the ERC has announced that it will depart from typical European funding schemes by deliberately ignoring the principle of 'juste retour' the concept that each country should benefit from European funding in the measure of its own contribution. The ERC has pledged to base its selection process strictly on excellence, using a peer review system. This means that all applicants located in or moving into a country of the European Union will compete against each other, regardless of their nationality.

Additionally, the ERC is targeting an area in which Europe is most deficient: providing young scientists with the means to become independent. The first call, for which the ERC will receive applications until April 25, is dedicated to applicants who obtained their PhD 2-9 years ago. These ERC Starting Grants, approximately 200 in the first year, will range from $€ 500,000$ to $€ 2$ million $(\$ 662,500-2,649,800)$ for a 5-year period, and will cover salaries of the principal investigator and staff as well as research-related costs. Another round of grants for more established researchers is expected later this year.

Projects funded by the ERC will still only represent a small proportion of research activities in Europe. Nevertheless, by extending competition across national borders and awarding grants that are both prestigious and generous, the ERC has the potential to elevate the overall level of research in Europe. At least, it could make the old continent a more attractive place to do research. Eventually, this may lead to alleviating the brain drain that Europe has endured for years. But meeting these ambitious hopes will require time and sustained support at multiple levels.

First, the ERC principles must be trusted by its political backers, and its independence must be respected. The European Parliament has been progressive in creating the ERC to abandon the principle of juste retour. Brussels should resist second-guessing this decision, even if the distribution of grants may not be geographically equitable.

Second, political support will have to translate into financial support. The ERC budget has already been drastically cut from the initial $€ 12$ billion ( $\$ 15.9$ ) projected over 7 years. The present $€ 7.5$ billion ( $\$ 9.9$ billion) budget is dangerously close to what the ERC director, Fotis Kafatos, cited in 2005 as the bare minimum to allow the ERC to make a difference and justify the effort (Nature 438, 723; 2005).

Finally, the ERC will need the support of the scientific community. The $95 \%$ acceptance rate from people approached to serve on reviewer panels is a good sign. The Starting Grants laureates will be in the spotlight as much as the ERC, whose success will be measured by how these researchers manage to establish themselves and secure funding beyond their ERC grant. These investigators will need all the help they can get. Becoming independent should not mean being alone; they will need access to the best facilities, talented graduate students, and a network of mentors and collaborators.

Priorities of the ERC have been set perfectly, and the momentum seems right. To capitalize on this, all stakeholders - researchers, institutions, reviewers, politicians and administrators - must commit to the success of the ERC as an organization trusted for its independence and excellence. Should it fail to meet the high expectations, a similar momentum will not be recreated for a long time. For the future of competitive European research, the ERC must succeed. 